\title{
El Hábeas Data en Colombia
}

Eduardo Cifuentes Muñoz

\section{Introducción}

En la República de Platón se refiere la fábula del anillo de Giges para demostrar que los "buenos lo son por su impotencia de ser justos". El antepasado del lidio Giges, pastor al servicio del Rey de Lidia, quien luego de ocurrido un terremoto que produjo una sima en el lugar donde apacentaba sus rebaños y sobrevenir otros hechos extraordinarios que omito, se apoderó de una sortija de oro. Pronto el humilde pastor descubrió los poderes singulares de la sortija: al volver la piedra hacia el interior de la mano se tornaba invisible y hacia fuera restauraba su visibilidad. Más tarde este poder será puntualmente utilizado para seducir a la reina, valerse de ella para matar al rey y apoderarse del reino. En el diálogo se invita a pensar que al entregar dos sortijas semejantes, una a persona justa y otra a persona injusta, no se producirá un comportamiento final diferente, puesto que ambos tenderán a abusar del inmenso poder.

Me interesa sólo anotar la forma cómo se describe la extensión del poder que se deriva de la sortija: “(...) hacer uso de lo ajeno, pudiendo a su antojo apoderarse en el mercado de lo que quisiera o introducirse en la casa de los demás para dar rienda suelta a sus instintos, matar y liberar a capricho, y realizar entre los hombres cosas que sólo un dios sería capaz de cumplir". Creo que la aspiración recóndita del poder absoluto en todos los tiempos no ha sido otra que la de tener la capa-

\footnotetext{
* Magistrado de la Corte Constitucional de la República de Colombia
} 
cidad de alternar visibilidad con invisibilidad. Tampoco dudo que el mayor poder posible surge de la posibilidad de obrar en el mundo real sin ser visto por ninguno. La situación de mayor indefensión y de carencia de poder, inversamente, es aquélla en que se encuentra aquél que es visto y está en imposibilidad de saberlo, pese a que se generen consecuencias materiales que lo afectan.

La tecnología moderna está creando poderes que se aproximan a los de la sortija de Giges. Los seres reales se disuelven en múltiples datos y así se observan por otros sujetos que operan desde la penumbra con un instrumento formidable que torna visibles a los demás. La ausencia de regulación y de control a los usos de las técnicas informáticas, podría expandir ilimitadamente el dominio del Estado o de los sujetos que disponen de poder informático. Una mercancía y un saber concreto que genera un potencial inimaginable de supremacía en la esfera social, se erige en amenaza cierta para la libertad y la democracia. Por consiguiente, la tecnología por lo menos algunos aspectos de ella, no puede ser ajena a la política y al Derecho.

La respuesta del Derecho, sin embargo, no se endereza a suprimir este nuevo factor de control social. El Hábeas Data representa apenas un intento incipiente y tímido dirigido a corregir distorsiones extremas del proceso comunicativo informático. De un lado, reduce en cierto grado la invisibilidad de los gestores o titulares de bancos de datos -lo que se logra exigiendo un registro de bancos, una declaración de sus objetivos y de sus procedimientos, etc.-; de otro lado, permite a las personas, en cierta medida, adquirir consciencia de su transparencia externa y de las condiciones de la misma, pudiendo incidir en la elaboración y transmisión de formatos singulares o unidimensionales de su personalidad y de sus acciones. La diferenciación entre información sensible y no sensible, resulta esencial para determinar la extensión y los límites de los poderes informáticos.

En el fondo, el Derecho legitima el poder informático. Si bien las regulaciones cumplen la función de domesticar este elemento de la modernidad, al mismo tiempo, implícitamente, no deja de reconocerse a la técnica el despiece del sujeto en multiplicidad de datos. Así se recabe -lo que es una victoria apreciable- para la persona humana la facultad de ser consciente de su sombra informática, es evidente que el Derecho Constitucional ha tenido que ceder a su idea originaria de 
sujeto en sentido "fuerte", la que comienza a presentarse en muchos ámbitos con el lastre de una pretensión utópica. Hasta el discreto encanto del anonimato, uno de los pocos dividendos de la sociedad de masas, pierde todo asomo de radicalidad en la sociedad tecnológico omnisciente, sin que el derecho pueda conservarla en su plenitud puesto que también éste imperceptiblemente ha refrendado el paradigma del ser corpuscular.

La idea de sujeto que subyace al principio de dignidad humana y a su múltiple e incesante traducción en derechos fundamentales, proviene del ideal emancipatorio de la Ilustración. Contra los reduccionismos de la ciencia, el Derecho Constitucional moderno ofrece un sujeto cuyo tejido lo lanza a un horizonte ilimitado de libertad y autorealización individual y social. A esta visión proteica se le comienza a aplicar una tasa de descuento, cuando al proceder a regular algunas aplicaciones tecnológicas en el campo de la informática, el Derecho, dentro de ciertos límites y condiciones, convalida el tratamiento informatizado del sujeto con arreglo a las exigencias funcionales de aparatos públicos y privados que sólo captan a la persona a partir de códigos y gramáticas fraccionadas.

Quiero simplemente decir que el derecho no sale indemne de su confrontación con la técnica. La regulación del Hábeas Data, positiva en términos generales e indispensable, como forma de sujetar la técnica al Derecho, ha tenido de todas formas un precio para éste que ha consentido -o se ha visto compelido a hacerlo- y justificado el tipo particular de la antropología que asume la tecnología informática, para la cual la persona humana se convierte en mero dato o conjunto de datos esparcibles y transmisibles a través de sus canales y a tenor de sus pulsaciones. Al final la regulación ha resultado funcional a la tecnología informática.

Dicho lo anterior, podrían formularse tres interrogantes:

(i) ¿Tiene algún sentido y cumple un propósito válido la consagración constitucional de un derecho como el Hábeas Data en un país en vía de desarrollo -vale decir, con índices apreciables de pobreza y reducida apelación a la tecnología-, cuando éste responde a exigencias novísimas de la protección de la dignidad humana propias de países que hacen un uso intenso y extenso de la tecnología?

(ii) ¿Así como se importa tecnología y sus manuales de uso, se habrá 
introducido su correlativa traducción inconstitucional que por fuerza luce exótica y demanda explicación?

(iii) ¿Qué función específica puede satisfacer, en sociedades como la colombiana, la positivización constitucional del derecho a la autodeterminación informativa?

Resulta, por lo menos paradójico, que haya sido el Hábeas Data, recogido en la nueva Constitución de 1991, una garantía de frecuente utilización por el ciudadano ordinario en los últimos años. Más sorprendente todavía es la circunstancia de que, casi en su totalidad, los amparos concedidos por los jueces se refieran a bancos de datos organizados por particulares y versen sobre datos económicos que en otros países no se comprenden dentro de la categoría de "información sensible". No obstante la recurrente invocación del Hábeas Data, aparte del texto constitucional que lo plasma, no se ha dictado hasta la fecha ninguna ley estatutaria que lo desarrolle. Como se verá, la ley ordinaria que pretendía hacerlo, fue declarada inconstitucional por la Corte Constitucional. Si se hace caso omiso de la norma constitucional, el Hábeas Data corresponde a un derecho típicamente pretoriano.

Podría, por ahora, intentarse dar una respuesta inicial a los interrogantes formulados, así fuese por el momento sumaria y provisional. El abuso del poder informático lamentablemente no es un privilegio de las sociedades avanzadas. También, en las menos desarrolladas, el uso del factor tecnológico, descubre sus facetas negativas y despliega su concierto de peligros y amenazas para la libertad, la identidad y la intimidad de las personas. En éstas últimas, la tecnología no pocas veces acentúa la asimetría reinante en el acceso, uso y disposición de los recursos del poder social. La frontera del control social y político aplicable a individuos y a colectivos, se fortalece y amplía enormemente cuando sólo pocas personas y grupos, gracias a la tecnología moderna, pueden hacer indiscriminado uso de la información a escala social.

Si la tecnología informativa tendencialmente exacerba desigualdades estructurales, comienza a ser ocioso preguntarse sobre la conveniencia de incorporar una herramienta jurídica enderezada a su uso correcto y en sentido humano. Así se trate de sociedades no generadoras de tecnología, sino usuarias y dependientes de los mercados de productos tecnológicos, no son ellas ajenas a los usos desviados del poder informático que lenta pero inexorablemente penetra en los distintos ámbitos de su quehacer colectivo. 
Debe agregarse que en las sociedades en vía de desarrollo, el Estado acopia una masa crítica ingente de datos -susceptibles de ser tratados y discriminados a través de su poder informático- provenientes de las personas pertenecientes a los sectores más pobres de la población a los cuales progresivamente extiende servicios y otorga prestaciones. Sin duda se han acrecentado las posibilidades de manipulación de las personas e, inclusive, de sojuzgamiento político de las "clientelas electorales".

Por lo demás, los derechos y garantías fundamentales, no de ahora, sino de antiguo, tienen carácter transcultural. No es extraño, pues, que las nuevas constituciones se nutran de las últimas conquistas de la dignidad humana, esta vez realizadas y percibidas en el escenario tecnológico que es propio de las comunidades avanzadas y que cada vez, con mayor fuerza, se entroniza en el mundo entero.

\section{El marco normativo}

\subsection{La Constitución Política}

Prescribe el artículo $15^{\circ}$ de la C.P. que "todas las personas (...) tienen derecho a conocer, actualizar y rectificar las informaciones que se hayan recogido sobre ellas en bancos de datos y en archivos de entidades públicas y privadas. En la recolección, tratamiento y circulación de datos se respetarán la libertad y demás garantías consagradas en la Constitución".

\subsubsection{Breve noticia sobre la adopción del texto}

El Gobierno propuso a la Asamblea Nacional Constituyente un texto del siguiente tenor:

“4. Toda persona natural o jurídica tendrá acceso a información sobre sí misma, salvo que la seguridad del Estado exija mantener la reserva, en los casos que establezca la ley. Toda persona tiene derecho a que se rectifique información falsa sobre sí misma, y a que ella no sea destinada a un fin distinto para el cual hubiere sido suministrada. 
5. La ley reglamentará el uso de la informática y de otros avances tecnológicos para garantizar la intimidad personal y familiar y el pleno ejercicio de otros derechos ${ }^{1}$.

Según el Gobierno, la iniciativa se encontraba plenamente justificada, pues, en su sentir:

"El cuarto apartado, establecería la posibilidad de obtener información personal, que se encuentre en archivos o base de datos. Este derecho que ha sido denominado "hábeas data", implicaría la posibilidad de ser informado acerca de los datos registrados sobre sí mismo y la facultad de corregirlos. Pretendería proteger la intimidad de las personas que se hayan visto asediadas por la creciente utilización de información personal por parte de la administración pública, de entidades financieras, educativas, profesionales u otras organizaciones privadas.

Si esta información se da a conocer sin ningún tipo de restricciones, se estaría usurpando la prerrogativa personal de determinar cómo se quiere aparecer, ante quién y en qué momento. La amenaza principal que se pretende evitar con la reforma sería la de que el individuo pierda el control sobre la propia información y no sepa quien pueda hacer uso de ella.

La única manera de solucionar este problema, es la de permitir única y exclusivamente a la persona natural o jurídica interesada el acceso a datos sobre sí misma, otorgándole, además la posibilidad de corregir o eliminar la información falsa. Esta facultad se restringiría sólo en el caso en que la seguridad del Estado exigiera mantener en reserva determinada información. La ley señalaría qué tipo de información se mantendría en reserva en forma temporal para que al cabo de varios años se puedan adelantar investigaciones históricas.

El último apartado del artículo se refiere a la informática y a otros avances tecnológicos. Las técnicas modernas, tales como los ordenadores o sistemas de procesamiento de datos, han per-

1 Presidencia de la República. Proyecto de Acto Reformatorio de la Constitución Política de Colombia. 
mitido el acceso desmedido a la información personal, y representan un nuevo fenómeno que amenaza el derecho a la intimidad. Es tal su trascendencia, que ha posibilitado la creación de bancos de datos, que contienen información personal fácilmente interconectable, proveniente de diversas fuentes, y que no se previó que pudieran ser vinculadas. Se constituye así toda una red de datos, que puede suministrar en segundos una información completa sobre cualquier persona. Estas redes aisladas no representan mayor peligro, pero en conjunto pueden vulnerar gravemente la intimidad del individuo. De esta manera, pacientes, ahorradores y empleados, quienes han tenido que suministrar en alguna oportunidad información sobre sí mismos, acabarían ignorando el empleo que de ella pueda hacerse.

La experiencia de otros países industrializados, muestra los conflictos característicos de una tecnología muy desarrollada. Dicha experiencia debería ser aprovechada para dotarnos de una gran regulación adecuada, que prevea las necesidades futuras. De hecho, el país ha iniciado ya la tecnificación de la información en todo tipo de entidades. Por ejemplo, la administración de justicia posee información sistematizada sobre órdenes de captura, condenas, etc. La centralización estatal o privada de la información puede atentar contra la intimidad de las personas, por lo que a partir de la norma propuesta, debería regularse la recolección de datos personales de manera tal que fuera una forma excepcional de obtener información, la cual debería estar orientada a un fin determinado inmodificable, que garantizaría el irrestricto acceso a la información personal. Para ello, se requiriría del control por parte de una autoridad especializada.

Disponer que la ley reglamenta el uso de la informática y de otros avances tecnológicos, para garantizar la intimidad personal y familiar y el pleno ejercicio de otros deberes, dejaría abierta la posibilidad de regular la informática, cuando en el futuro derechos diferentes al de la intimidad, se encuentren amenazados por estos avances tecnológicos ${ }^{2} "$.

2 Presidencia de la República: Proyecto de Acto Reformatorio de la Constitución Política de Colombia. Op. cit. 
En el seno de la Asamblea Nacional Constituyente, a juzgar por lo que se expresa en sus actas, no se desarrolló ningún debate de fondo sobre el contenido y alcance del Hábeas Data.

\subsubsection{Naturaleza y ubicación del derecho}

El Hábeas Data se incluye en el capítulo 1 del título II de la C.P., en el que se enuncian los Derechos Fundamentales. Aunque en estricto rigor el Hábeas Data corresponde a un específico proceso constitucional ideado para cumplir diversos propósitos, en la Constitución se enuncian, a título de derecho sustantivo varias facultades de la persona concernida por los datos y se confía a la acción de turela, en principio, su protección judicial. Si bien la Corte Constitucional se ha limitado a conferir a la ubicación de los derechos bajo el mencionado capítulo y epígrafe, un valor meramente ilustrativo o indicativo de la naturaleza de un determinado derecho -no enteramente conclusivo-, no se ha puesto jamás en duda que el Hábeas Data ostente la condición de derecho fundamental.

De otro lado, no deja de tener alguna significación que el artículo $15^{\circ}$ de la C.P., en el que se regula el Hábeas Data, se ocupe básicamente del derecho a la intimidad personal y familiar y de la inviolabilidad de la correspondencia, además de establecer una excepción a la reserva de documentos privados.

De hecho, la Corte Constitucional, en un primer momento, no dudó en acomodar conceptualmente el Hábeas Data dentro del ámbito del derecho a la intimidad ${ }^{3}$. En esa oportunidad se precisó que la intimidad se proyectaba en dos dimensiones: como secreto de la vida privada (sentido estricto) y como libertad (sentido amplio). La primera dimensión ofrecería la visión tradicional de la intimidad marcadamente individualista y portadora de facultades de exclusión de signo negativo. La segunda, conferiría a la intimidad el carácter de libertad pública y la habilitaría para enfrentar las amenazas que en el mundo moderno se ciernen sobre ella. Concluye la Corte: “(...) en las nuevas condiciones creadas por la emergencia de sofisticadas tecnologías, la intimidad adquiere más y más objetiva naturaleza política como que apunta a lograr

3 Corre Constitucional, Sentencia T-414 del 16 de junio de 1992 
un justo equilibrio en la distribución del poder de la información y no exclusivamente, como en el pasado, a garantizar los apetitos de la soledad de una persona".

Posteriormente, en la sentencia de unificación jurisprudencial SU082 del $1^{\circ}$ de marzo de 1995 , la Corte rectificará el anterior criterio y atribuirá al Hábeas Data una configuración autónoma y propia como quiera que "a diferencia de lo que ocurre en otras legislaciones, en Colombia el Habeas Data está expresamente establecido en la Constitución". En esta ocasión la Corte señaló que el núcleo esencial del Hábeas Data estriba en la defensa del derecho a la "autodeterminación informática", en cuya virtud la persona a la cual se refieren los datos que reposan en un archivo público o privado está autorizada para permitir su conservación, uso y circulación.

Dos consecuencias principales se siguen de la caracterización del Hábeas Data como derecho fundamental. De una parte, la regulación de este derecho y la determinación de los procedimientos y recursos para su protección sólo pueden consagrarse a través de leyes estatutarias (se aprueban por mayoría absoluta de los miembros del Congreso dentro de una sola legislatura y su trámite comprende la revisión previa de la constitucionalidad del proyecto por parte de la Corte Constitucional).

De otra parte, entre los mecanismos de defensa judicial del derecho, se destaca la acción de tutela que puede reclamarse ante cualquier juez, en todo momento y lugar, mediante un procedimiento preferente y sumario. Con el objeto de ilustrar la efectividad de la tutela, basta señalar que por disposición constitucional "en ningún caso podrán transcurrir más de diez días entre la solicitud de tutela y su resolución". Las sentencias de tutela se remiten a la Corte Constitucional para su eventual revisión.

\subsection{La ley estatutaria}

A partir de la Constitución de 1991, las personas cuyos datos encontraban desde hacia varios lustros almacenados en bancos de datos organizados por entidades del sector financiero y que eran reportadas como deudores morosos, entablaron con éxito acciones de tutela dirigidas a corregir o eliminar, por diversas circunstancias, sus nombres de tales registros. 
Los bancos y demás instituciones financieras se constituyeron en activo grupo de presión ante el Congreso a fin de que éste expidiera la Ley Estatutaria respectiva y por esta vía "frenara los excesos de la tutela". El Congreso dictó, finalmente, el proyecto de Ley $N^{\circ} 127 / 93$ Cámara, 12/93 Senado, mediante el cual "se dictan algunas disposiciones sobre el ejercicio de la actividad e recolección, manejo, conservación y divulgación de Información Comercial". El texto de la ley, que se transcribe en el anexo, buscaba restringir al máximo el Hábeas Data referido a bancos de datos financieros y a este fin circunscribía básicamente su objeto.

La Corte Constitucional, mediante sentencia C-008 del 17 de enero de 1995, declaró la inconstitucionalidad del proyecto de ley. El citado proyecto había sido aprobado sin contar con la mayoría especial exigida por la Constitución Política. La violación de la Constitución no podía ser más flagrante. De todas maneras, la inexistencia de una ley estatutaria que regule la materia, si bien deplorable por muchos aspectos, no llega a afectar la efectividad del Hábeas Data, por tratarse, a veces del artículo $85^{\circ}$ de la C.P., de un derecho de aplicación inmediata, que no requiere en estricto rigor de la interpositio legislatoris.

\section{Contenido y elementos del Hábeas Data}

En ausencia de la ley estatutaria ha sido la jurisprudencia de la Corte Constitucional la encargada de delinear los contornos del Hábeas Data y desarrollar sus aspectos más relevantes. En ninguna otra materia, como en ésta, las sentencias de la Corte Constitucional, se han convertido en fuente generadora de reglas y criterios jurídicos. Por consiguiente, en base a lo expresado por la Corte se procederá a exponer tanto el contenido como los alcances del Hábeas Data.

\subsection{Contenido}

Ya se anticipó que para la Corte Constitucional el centro de gravedad del Hábeas Data viene a estar constituido por la "autodeterminación informática" y por la libertad. Dicha autodeterminación se traduce en la facultad de la persona concernida por los datos almacenados en un archivo público o privado para autorizar su conservación, uso y circula- 
ción, lo mismo que para conocerla, actualizarla y rectificarla. Estas facultades se consideran indispensables puesto que sin ellas la circulación libre de la información podría lastimar tanto la identidad de la persona como su libertad. Se descubre, de este modo, una dimensión inédita, pero necesaria, de la autonomía personal: la necesidad de controlar el flujo de información que sobre la persona y sus actos se vierte hacia el exterior y que se reproduce incesantemente a través de los canales informáticos.

\subsection{Sujetos}

En principio, puede decirse que sujeto activo del Hábeas Data es toda persona, natural o jurídica, cuyos datos particulares sean captados en un archivo público o privado "susceptible de tratamiento automatizado", como lo ha puesto de presente la Corte Constitucional.

La Corte Constitucional ha reconocido que dependiendo de la naturaleza de cada derecho fundamental en concreto, las personas jurídicas pueden ser titulares activos de posiciones iusfundamentales. Desde este punto de vista, nada se podría oponer a que las personas jurídicas pudiesen, en este caso, ser consideradas titulares activos del Hábeas Data. La misma consideración del Hábeas Data como derecho autónomo, cuya configuración trasciende el ámbito de la intimidad, contribuye a justificar aún más la posibilidad de extender a las personas jurídicas la titularidad del mencionado derecho.

Por el aspecto pasivo, los sujetos potencialmente obligados serían todas aquellas personas naturales o jurídicas, públicas o privadas, que organicen bancos de datos diseñados con el fin de poner en circulación los datos que almacenen o con aptitud para hacerlo y generar información a terceros.

\subsection{Facultades del sujeto activo}

La Constitución Política precisa las facultades de la persona a la cual se refieren los archivos públicos o privados:

a. El derecho a conocer las informaciones que se produzcan de ella y que se contienen en tales archivos;

b. El derecho a solicitar y obtener la actualización de la información recogida en los archivos; 
c. El derecho a rectificar las informaciones inexactas, falsas o que en general no correspondan a la verdad.

\subsection{Otras facultades}

La Corte Constitucional, por vía jurisprudencial, refiriéndose a los bancos de datos financieros o económicos, ha reconocido en cabeza de toda persona el "derecho a la caducidad del dato negativo", el cual se infiere, en su concepto, del principio de autodeterminación informática y de la misma cláusula de libertad.

A este respecto ha señalado la Corte: "(...) también hacia el pasado debe fijarse un límite razonable, pues no sería lógico ni justo que el buen comportamiento de los últimos años (se refiere al deudor moroso) no borrara, por así decirlo, la mala conducta pasada. (...) Es claro, pues, que el término para la caducidad del dato lo debe fijar, razonablemente, el legislador. Pero, mientras no lo haya fijado, hay que considerar que es razonable el término que evite el abuso del poder informático y preserve las sanas prácticas crediticias, defendiendo así el interés general".

Con base en estas premisas la Corte considera que sería irrazonable la conservación, uso y divulgación informática del dato financiero, si se omite la ocurrencia de todos los siguientes hechos:

a. "Un pago voluntario de la obligación";

b. "Transcurso de un término de dos años, que se considera razonable, término contado a partir del pago voluntario". "Expresamente se exceptúa el caso en que la mora haya sido inferior a un año, caso en el cual, el término de caducidad será igual al doble de la misma mora"; $y$,

c. "Que durante el término indicado en el literal anterior, no se hayan reportado nuevos incumplimientos del mismo deudor, en relación con otras obligaciones".

No deja por fuera la Corte tres eventos que pueden ocurrir: el pago de la obligación en un proceso ejecurivo; el pago producido una vez presentada la demanda, con la sola notificación del mandamiento de pago; y, finalmente, el no pago de la obligación al prosperar la excepción referida a la prescripción. En el primer caso, a juicio de la Corte, 
el término de caducidad sería de cinco años (semejante al término de prescripción de la pena de los delitos que no tienen señalada una pena privativa de la libertad). En el segundo caso, se aplicará la regla general y el término de caducidad será solamente de dos años. En el tercer caso, no se presenta la caducidad, puesto que "no ha habido pago y, además, el dato es público".

\subsection{El dato y su titularidad}

El alcance del Hábeas Data, en particular su función como derecho reivindicativo de un espacio de libertad frente al poder informático, resulta inaprehensible si no se discurre sobre el concepto de DATO, entidad básica que conforma los bancos de datos y que constituye aquello que se predica, de una o de otra manera, del sujeto concernido.

Según el concepto del experto Lleras que la Corte prohija "el dato es un elemento material susceptible de ser convertido en información cuando se inserta en un modelo que lo relaciona con otros datos y hace posible que el dicho dato adquiera sentido" (Corte Constitucional, sentencia T-414 de 1992).

El dato, prosigue la Corte, como elemento básico de información sobre eventos o cosas, referido a una específica persona, provee información sobre su identidad o al menos un aspecto de ésta. La reunión de un conjunto de estos datos, lo que está al alcance de la tecnología actual, puede brindar a terceros un perfil virtual de la persona.

El "poder informático" justamente surge de la posibilidad que se dispone para almacenar datos personales y poder discriminarlos con apoyo en sistemas y canales electrónicos. Los peligros para la libertad, la identidad y la intimidad de las personas se acrecientan. Las personas súbitamente pueden ser objeto de respuestas o acciones hostiles, rechazos de variada intensidad, coerciones ocultas, cuando no de invitaciones y ofertas no deseadas. La transparencia de la identidad y, naturalmente, su distorsión, ambas no autorizadas ni buscadas, ciertamente representan una evidente "contaminación" de las libertades, como ha dado en llamarse este fenómeno de abuso del poder informático.

Como necesario contrapeso -afirma la Corte en la sentencia citada"este nuevo poder ha engendrado la libertad informática. Consiste ella en la facultad de disponer de la información, de preservar la propia identidad informática, es decir, de permitir, controlar o rectificar los 
datos concernientes a la personalidad del titular de los mismos y que, como tales, la identifican e individualizan ante los demás".

$\mathrm{Si}$ bien en varios momentos diversas personas pueden acceder al conocimiento de un dato, su propiedad, asevera la Corte, no puede tener los rasgos que distinguen el derecho de dominio clásico, puesto que no podrán excluirse completamente las pretensiones del sujeto concernido por aquél y que, en los términos de la Constitución Política, le permite conocer, rectificar y actualizar las informaciones respectivas, particularmente con el objeto de evitar y controlar el abuso del poder informático.

En el caso concreto de los bancos de datos financieros, en la sentencia SU-082 de 1995, la Corte señaló que “(...) así como la facultad de reportar a quienes incumplan las obligaciones con ellos contraídas, tiene como base fundamental y punto de equilibrio, la autorización que el interesado les otorgue para disponer de esa información, pues al fin y al cabo, los datos que se van a suministrar conciernen a él, y por tanto, le asiste el derecho, no sólo a autorizar su circulación, sino a rectificarlos o actualizarlos, cuando a ello hubiere lugar". Autorización que debe ser expresa y voluntaria por parte del interesado para que sea realmente eficaz.

\subsection{Protección judicial del derecho}

2.6.1. En vista de que no se ha dictado, hasta la fecha, la ley que desarrolle este derecho y que disponga un mecanismo o procedimiento específico para su protección, la acción de tutela es por el momento el medio idóneo para reclamar su protección en los eventos de violación o de amenaza.

La acción de tutela, regulada en el artículo $86^{\circ}$ de la C.P., se caracteriza por su probada eficacia para defender la efectividad de los derechos fundamentales. La revisión eventual de las sentencias que se profieran, por parte de la Corte Constitucional, de otro lado, ha permitido que progresivamente se conforme un cuerpo doctrinal que orienta la actividad judicial y que está atenta a adaptar los fallos a los nuevos retos y desafíos que enfrentan los derechos.

2.6.2. Si bien a través de la acción de tutela se puede solicitar, y obtener, la condigna indemnización por concepto del daño emergente a cargo de quien ha vulnerado o puesto en peligro un derecho fundamental, la Corte excepcionalmente la ha impuesto. 
2.6.3. La acción de tutela procede contra particulares en los casos que determine la ley. En relación con el Hábeas Data no cabe la menor duda de que la acción de tutela puede intentarse contra particulares. En efecto, dispone el artículo $42^{\circ}$ del Decreto $N^{\circ} 2591$ de 1991:

\section{"Artículo 42. Procedencia}

La acción de tutela procederá contra acciones u omisiones de particulares en los siguientes casos:

(...).

6. Cuando la entidad privada sea aquella contra quien se hubiere hecho la solicitud en ejercicio del hábeas data, de conformidad con lo establecido en el artículo $15^{\circ}$ de la Constitución".

Cabe añadir que prácticamente en su totalidad las acciones de tutela entabladas para garantizar el derecho analizado, se han enderezado contra particulares que administran bancos de datos.

\section{Problemas adicionales sobre archivos públicos o privados}

\subsection{Informaciones sobre personas que el Estado recopila y registra en sus archivos.}

La Corte Constitucional en la sentencia T-444 de 1992, entró a analizar el tema relacionado con las investigaciones que lleva a cabo el Estado a través de sus organismos de inteligencia. La demandante, detenida en una cárcel, sindicada del delito de rebelión, solicitaba que fueran eliminados los antecedentes allegados al proceso por organismos de inteligencia, que la vinculaban como integrante del denominado "Ejército de Liberación Nacional".

La Corte, luego de analizar los antecedentes y extenderse sobre el alcance del Hábeas Data, concluyó que toda persona tiene el derecho a que de ella se conozca sólo lo mínimo para asegurar la normal convivencia social. A su turno según la Corte, el Estado tiene la potestad de conocer "lo máximo necesario" para la debida protección de los ciudadanos y las instituciones. 
Advierte la Corte en la sentencia: “(...) el Estado (puede) incluso recopilar y archivar información sobre una persona, en el marco de sus legítimas y democráticas funciones, siempre y cuando no divulgue ni de a la publicidad por ningún medio la información sobre esa persona, salvo el evento de que ella tenga antecedentes penales o contravencionales, esto es, que tenga una condena proferida en sentencia judicial definitiva, como lo dispone el artículo $248^{\circ}$ constitucional".

En la sentencia no se rechaza el "cruce" de informaciones dentro del Estado, el cual se justifica en virtud del "principio tácito de colaboración y reserva de información entre instancias del Estado", siempre que ello se encuentre previamente autorizado por el ordenamiento. Empero, si la información que se comparte dentro del Estado, es susceptible de ser conocida por terceros, la misma no podrá contener datos perjudiciales, distintos de los "antecedentes" de que trata el artículo $248^{\circ}$ de la Constitución Política (condenas proferidas en sentencias judiciales firmes).

La Corte efectúa una distinción entre "recopilación" de la información y el "resultado" de la investigación. Sobre este particular señala:

"En la recopilación los organismos del Estado poseen una facultad amplia y sólo están limitados por los principios de respeto de los derechos humanos, por el debido proceso y por una reserva absoluta.

En cuanto al resultado, éste sólo puede ser conocido por el interesado directamente cuando forme parte de un proceso ante la jurisdicción penal, disciplinaria o fiscal, y allí pueda a través de los principios de contradicción de la prueba, cuestionar su legalidad a la luz del análisis probatorio que deberá realizar el funcionario competente.

Pero la recopilación y las evaluaciones internas son absolutamente reservadas; ellas son el soporte científico del resultado. A través de ellas se detecta la información y de su reserva precisamente se deriva, como se mencionó anteriormente, el éxito de una investigación.

El interesado tiene derecho a conocer de los archivos reservados sólo aquella información que le es necesaria para casos especiales. Es así como el Decreto $N^{\circ} 2398$ de 1986 permite que el 
interesado solicite los antecedentes de sus respectivos registros. Es decir sobre los registros podrá ejercer el derecho que le otorga el artículo $15^{\circ}$ de la Constitución para conocer, actualizar o rectificar las informaciones que se hayan recogido en bancos de datos y en archivos de entidades públicas y privadas, únicamente cuando la información ha salido de los organismos de inteligencia del Estado y se encuentra ya en manos de las autoridades competentes para adelantar procesos judiciales.

De los resultados o los soportes de la información son titulares las personas cuyos datos hayan sido reportados y en consecuencia tienen derecho a conocer, actualizar y rectificar las informaciones que no sean reservadas.

La ley protege la reserva y es así como sanciona su violación en los artículos $155^{\circ}$ (utilización de asunto sometido a secreto o reserva), delito consagrado dentro del capítulo de los abusos de autoridad y otras infracciones y $289^{\circ}$ (divulgación y empleo de documentos reservados), tipificado dentro del capítulo de los delitos contra la liberta individual y otras garantías, o la Ley $\mathrm{N}^{\circ}$ 57 de 1985 que establece en el artículo $12^{\circ}$ :

"Toda persona tiene derecho a consultar los documentos que reposan en las oficinas públicas y a que se le expida copia de los mismos, siempre que dichos documentos no tengan carácter reservado conforme a la Constitución o la ley, o no hagan relación a la defensa o seguridad nacional ${ }^{4}$ ".

Finalmente, concluye la Corte:

"Si los organismos de inteligencia del Estado tienen reseñada en calidad de "rebelde" a la peticionaria, ello es conforme a derecho siempre y cuando no sea dado a conocer por fuera de los organismos.

Si un tercero o la misma accionante solicitan acceso a la información que el Estado tiene de ésta, las entidades oficiales competentes sólo podrán decir que -no estando condenada sino sólo detenida-, ella no tiene ningún tipo de antecedentes.

4 Corte Constitucional, Sentencia T-444 del 7 de julio de 1992. 
Si del resultado del proceso que cursa en el Juzgado de Orden Público se demuestra que la peticionaria es absuelta de todo delito que presuntamente ella ha cometido, el Juez competente está en la obligación de informar a las autoridades y a los organismos de inteligencia que adecuen su información a lo resuelto en el proceso.

Asimismo, si el Juez advierte que, antes de que la información sea asequible a terceros, esto es, antes del juicio, aquélla no ha sido debidamente reservada y se ha filtrado a la opinión pública, deberá adoptar las medidas conducentes para investigar los delitos y demás infracciones a que hubiere lugar, con el fin de proteger, ahí sí, la intimidad de la peticionaria".

\subsection{La utilización de datos tributarios por parte del Estado para fines diversos}

Tal vez el retrato más cercano de la persona y de su actividad -por lo menos desde el punto de vista económico- es el que gracias a las declaraciones tributarias, puede reconstruir el Estado y sus funcionarios.

La Corte Constitucional en la sentencia T-145 de 1993 consideró que el Estado no había violado la reserva tributaria (D. 624 de 1989, Arts. $583^{\circ}$ y $584^{\circ}$ ) a raíz de la cancelación de la inscripción de un contratista en el registro de constructores del Ministerio de Obras Públicas y Transporte, luego de verificar, mediante un cruce de informaciones con el Ministerio de Hacienda y Crédito Público, que los valores que aparecían en las declaraciones de renta presentadas para la renovación de la inscripción diferían de los valores que reposaban en la Administración de Impuestos Nacionales.

Si bien la Corte reconoce, en la sentencia, que la reserva tributaria impide a los funcionarios utilizar la información confiada por los declarantes para fines diversos del control, recaudo y determinación de los impuestos, admite, de otra parte, que la administración para la protección de los intereses públicos, puede confrontar la información que se le suministra -con el fin de obtener una ventaja o situación favorable- con la que dispone en sus bancos de datos.

En materia tributaria, sin embargo, la consulta intraestatal, no puede referirse, expresa la Corte, ni a las bases gravables ni a la determi-

5 Corte Constitucional, Sentencia T-444 del 7 de julio de 1992. 
nación privada de los impuestos. En otras palabras, el contratista, en este evento, no podía invocar el Hábeas Data para impedir que el Estado investigase la autenticidad de las informaciones suministradas.

\subsection{Derecho a información vital en circunstancias excepcionales}

La Corte ha establecido que la consagración del Hábeas Data no comporta - por fuera de los archivos sujetos a tratamiento informático- el derecho genérico a conocer información de personas públicas o privadas con fines distintos de los de controlarla, actualizarla y rectificarla. Lo anterior, desde luego, deberá entenderse sin perjuicio de la libertad de acceso a los documentos y archivos públicos, salvo las excepciones que establezca la ley (C.P. Art. $74^{\circ}$ ).

En dos situaciones la Corte ha establecido que, independientemente de la existencia o no de un archivo informatizado, vale decir, por fuera del esquema del Hábeas Data, una persona puede requerir de otro particular información o datos que le son relevantes y que éste último está en la obligación de suministrar.

En el primer caso, el padre anciano e indigente, que había facultado a su hijo para enajenar su único bien, en vano había intentado tener alguna noticia sobre la suerte del negocio de cuyo resultado dependía su bienestar futuro. En esta oportunidad la Corte señaló:

"El ocultamiento de la información de un negocio a quien está vitalmente interesado en él, configura una conducta que coloca a la persona en situación de indefensión, respecto del contratante que abusa de su posición privilegiada. La solidaridad debe gobernar las relaciones entre las partes contratantes, particularmente entre las personas con intereses comunes en el negocio. No obstante, el incumplimiento del deber de informar acerca del desarrollo de un contrato a la persona interesada en él, es una materia que debe ser resuelta exclusivamente con base en la ley, pues, carece de relevancia constitucional, salvo que la omisión materialmente vulnere de manera directa los derechos fundamentales de quién depende en grado sumo de las resultas del mismo para su subsistencia autónoma y libre, siempre que en este caso excepcional se acredite, además de la insuficiencia de 
los remedios legales, que la omisión es la causa eficiente de la transgresión ${ }^{6} "$.

En el segundo caso, la demandante que había sido internada, inconsciente y en avanzado estado de embarazo, en una clínica privada, creía que había dado a luz una niña. Según el establecimiento médico, a la paciente se le practicó una cirugía y el feto fue encontrado muerto. Aparte de la historia clínica, no se aportó en ningún momento, por el desorden de los archivos existentes el oficio de rigor dirigido al cementerio a fin de acreditar la inhumación de la criatura.

En la sentencia de la Corte se expresa lo siguiente:

"La situación de postración y tristeza en que se encuentra la señora Larrea Guevara por desconocer si su hija murió y, en dado caso, el lugar donde fue enterrada, se origina en las irregularidades administrativas de la Clínica de Maternidad "Rafael Calvo". El manejo de los archivos de la entidad y la falta de diligenciamiento de los documentos legales requeridos para la inhumación del feto, vulneran el derecho a la información mínima vital $y$, consecuencialmente, el derecho a la seguridad personal de la peticionaria.

La omisión de la entidad de salud vulneró el derecho fundamental a la información mínima vital de la peticionaria. La negativa a entregar la información necesaria para tener certeza de la muerte de su hija -copia del certificado de defunción fetal, comunicación de envío del cuerpo al cementerio local, relación de los nacimientos acaecidos en la Clínica de Maternidad "Rafael Calvo" durante el año 1987, copia de los libros de anotaciones y registros, etc.-, compromete grave y directamente los derechos de la peticionaria a la integridad mental, al libre desarrollo de la personalidad y a la seguridad personal, al condenarla a vivir en la duda permanente, lo que afecta su esfera afectiva, sus proyectos vitales y su salud física y mental ${ }^{7}$.

6 Corte Constitucional, Sentencia T-125 de 1994.

7 Corre Constitucional, Sentencia T-443 de 1994 
En la citada providencia, de orro lado, se alude a la conservación de archivos como deber correlativo al derecho de información mínima vital:

"Consustancial al derecho de información mínima vital (C.P. Arts. $94^{\circ}, 1$ y 2) es el deber de mantener un archivo de la información que permita a los pacientes conocer todas las circunstancias relacionadas con la intervención médica, ya que su conocimiento es condición necesaria para la efectividad de otros derechos fundamentales. La historia clínica, si bien representa parte importante de la memoria de las condiciones y el tratamiento seguido a una persona, no constituye toda la documentación existente en las entidades de salud respecto de una persona.

Los archivos son el reflejo documentario de la actividad práctica, jurídica o administrativa de una persona o institución. Por archivos públicos se entiende los documentos producidos por una entidad oficial o privada encargada de la prestación de un servicio público, en el desarrollo de sus actividades o competencias y los cuales se organizan y conservan según el orden natural de funcionamiento de la entidad. Se dice con sobrada razón que "el archivo refleja la institución que lo ha producido".

Históricamente, los archivos han sido parte esencial de la civilización. Aristóteles los consideraba indispensables en un Estado modelo. A Napoleón se atribuye la máxima según la cual "un buen archivista es más necesario que un buen general de artillería". Las sociedades que no disponen de archivos son sociedades sin memoria. Sin ellos, en la práctica, no existiria organización estatal.

Ahora bien, un archivo no es la simple recopilación o colección de documentos. El archivo es un conjunto orgánico de documentos, unidos por un vínculo originario o de procedencia, que sirven para recuperar con agilidad y en tiempo oportuno toda la información almacenada por una oficina o institución en el curso de su actividad.

La vulneración o amenaza del derecho a conocer una información personal puede presentarse, entonces, por la deficiente organización, conservación o custodia de los archivos de las entidades de salud". 


\section{CONCLUSIONES}

1. La regulación constitucional y legal de los desarrollos tecnológicos en el campo de la informática, obedece a la necesidad de controlar los abusos del poder informático que pueden afectar gravemente la libertad y los derechos de la esfera personal.

2. La sujeción de la tecnología informática a los dictados del derecho, corrige sus distorsiones, pero, en términos generales, contribuye a convalidarla socialmente. Como saldo negativo de esta confrontación, se anota el progresivo marchitamiento de la idea de sujeto "en sentido fuerte", en la que tradicionalmente ha descansado el constitucionalismo occidental.

3. En los países en vía de desarrollo, la positivización constitucional del Hábeas Data se justifica, pese a que las aplicaciones informáticas sean incipientes. El poder informático, público y privado, no puede quedar exento de una regulación mínima. No hacerlo significaría, simplemente, acrecentar los espacios de poder de sus actuales detentadores.

4. La Constitución Política de Colombia consagra el Hábeas Data que verdaderamente responde al esquema de un proceso constitucional, como derecho sustantivo que otorga a su titular la facultad de conocer, actualizar y rectificar las informaciones que se hayan recogido en archivos públicos y privados y que le conciernan.

5. Hasta la fecha no se ha dictado la ley estatutaria prevista en la Constitución cuyo objeto sería desarrollar el Hábeas Data. El proyecto que se dictó, fue declarado inconstitucional por la Corte Constitucional.

6. Con ocasión de las controversias suscitadas alrededor de las informaciones contenidas en algunos bancos de datos de instituciones financieras, la Corte Constitucional, en Sala de Revisión de Tutelas, ha elaborado un cuerpo doctrinario sobre el Hábeas Data que, en cierta medida, suple la ausencia de ley estatutaria en la materia.

7. Si bien la jurisprudencia de la Corte se ha referido sólo a un tipo de banco de datos - de naturaleza económica o financiera- cuyas informaciones, además, no comprometen áreas sensibles de la personalidad, los criterios establecidos pueden ofrecer un marco general al Hábeas Data. En particular, la jurisprudencia ha precisado el carácter, contenido y alcance del Hábeas Data, las facultades de las personas concernidas y las obligaciones de los gestores de los archivos. 
La índole de los problemas debatidos no ha permitido a la Corte ocuparse de aspectos tan esenciales como los relativos al derecho de exclusión y de confidencialidad. De otra parte, los conflictos que suscitan los bancos de datos financieros en relación con otros derechos como el buen nombre, la intimidad y el honor, para enumerar sólo estos, no tienen el grado de tensión que comparten bancos de datos diferentes. En este sentido, la doctrina de la Corte sobre conflictos del Hábeas Data con otros derechos, no ha abarcado los eventos que son más pugnaces.

8. Es indispensable que se dicte la ley estatutaria sobre el Hábeas Data, no obstante que para su efecrividad ello no sea necesario y que, hasta el presente, la jurisprudencia de la Corte Constitucional haya llenado, parcialmente, este vacío. Sin embargo, esta situación de suyo precaria no se compadece con la vigencia real del principio democrático. De otro lado, la jurisprudencia, por definición casuista, no puede contemplar el conjunto de eventos y de asuntos que normalmente integran una normativa exhaustiva en esta materia. No se puede ignorar que la jurisprudencia de la Corte se ha generado en torno de los bancos de datos financieros, y sólo marginalmente se ha referido a otros bancos de datos. Normas especiales de protección se requieren en relación con los bancos de datos de las entidades públicas y sobre los bancos de datos en campos tan importantes como el empleo, la salud, la educación, entre otros.

\section{ANEXO \\ CÁMARA DE REPRESENTANTES \\ PROYECTO DE LEY N ${ }^{\circ}$ 127/93 CÁMARA, 12/93 SENADO}

Por la cual se dictan algunas disposiciones sobre el ejercicio de la actividad de recolección, manejo, conservación y divulgación de Información Comercial.

\section{EL CONGRESO DE LA REPÚBLICA DECRETA:}

ARTÍCULO $1^{\circ}$. PROTECCION DE LA INTIMIDAD Y EL BUEN NOMBRE: De conformidad con los artículos $15^{\circ}$ y $21^{\circ}$ de la Constitución Nacional, nadie puede ser objeto de injerencias arbitra- 
rias o abusivas en su vida privada, en la de su familia, en su domicilio o en su correspondencia, ni de ataques ilegales a su honra o su reputación.

Asimismo, y de conformidad con el artículo $20^{\circ}$ de la Constitución Nacional, toda persona tiene derecho a recibir información objetiva veraz e imparcial.

ARTICULO 20. AMBITO DE APLICACION: La presente ley se aplicará a las personas y entidades que ejerzan la actividad de recolección, manejo, conservación y divulgación de Información Comercial.

La información sobre las personas no podrá ser recogida y procesada de manera injusta, fraudulenta o ilegal, ni ser utilizada para fines contrarios a los propósitos y principios de la Constitución Nacional y de la Carta de las Naciones Unidas.

Por Información Comercial se entenderán todos los datos relevantes para la toma de decisiones, tales como: experiencias en manejo de obligaciones y relaciones comerciales, bancarias, crediticias y de negocios, estados e indicadores financieros e información sobre la solvencia económica de las personas, sobre sus operaciones, sus actividades, su experiencia y trayectoria.

\section{ARTÍCULO $3^{\circ}$. LEGITIMIDAD DE LAS BASES DE DATOS:} Cualquier persona puede crear un banco de datos o archivo y recolectar información que no pertenezca a la intimidad de otros. Estos datos son de libre circulación, en las condiciones de la presente ley.

Para los efectos de la presente ley, se entiende por banco de datos, todo conjunto organizado de información de carácter personal, cualquiera que fuera la forma o modalidad de recolección, almacenamiento y de la recuperación de la información, ya sea efectuada por entidades públicas o privadas, con la intención de proveerla a terceros con propósitos comerciales.

La información puede ser de aquella que pertenece al dominio público y a la cual puede y debe tener acceso cualquier persona de conformidad con lo dispuesto en los artículos $15^{\circ}$ y $74^{\circ}$ de la Constitución Nacional; o de aquella que consiste en el registro histórico, respecto de ellas, del comportamiento y hábitos de pago en relación con obligaciones crediticias, del manejo de cuentas corrientes, de sus transacciones comerciales, sus antecedentes o referencias laborales; y en 
general, datos de contenido patrimonial, laboral o comercial que por lo tanto no hacen parte de su intimidad, salvo en cuanto estén amparados por lo dispuesto en el último inciso del artículo $15^{\circ}$ de la Constitución Nacional.

PARÁGRAFO $1^{\circ}$. Las entidades públicas que manejen bancos de datos o archivos de Información Comercial no podrán suministrar a terceros información, que en desarrollo del artículo $15^{\circ}$ de la Constitución, esté amparada por reserva y sea de naturaleza íntima, salvo que la persona a quien concierna la información lo autorice por escrito. La reserva no es oponible a las autoridades que requieran la información en ejercicio legítimo de sus funciones, pero en tal caso aquellas deberán guardar la confidencialidad de dicha información. Tampoco se puede oponer reserva a la persona concernida en la información, excepto tratándose de los archivos policiales, sobre la seguridad nacional y asuntos criminales cuando así lo establezca la ley.

PARÁGRAFO $2^{\circ}$. Los bancos de datos o archivos no podrán recolectar información íntima de aquella a la cual se refiere el inciso último del artículo $15^{\circ}$ de la Constitución Nacional ni, por ende, suministrarla a terceros, pues ella sólo podrá ser presentada por los interesados para efectos tributarios o judiciales, en los casos de inspección, vigilancia e intervención del Estado, y en los términos que señale la ley.

ARTÍCULO 40 REGLAS DE FUNCIONAMIENTO: Todo aquel que ejerza la actividad a que se refiere el artículo anterior deberá sujetarse a las siguientes reglas:

A. La Información Comercial solamente podrá ser divulgada para los fines específicos para los cuales se recopiló, y no podrá ser usada para coaccionar de manera ilegítima a personas o entidades, o para ejercer arbitrariamente el propio derecho, ni para fines distintos de los del último inciso del artículo $15^{\circ}$ de la Constitución Nacional, en los términos de la presente ley.

B. No podrá existir archivos o registros secretos de Información Comercial y toda persona tendrá acceso a la información o datos que sobre ella se conserven, así como a solicitar su rectificación o actualización, sin perjuicio de las normas especiales relativas a la seguridad nacional, prevención, control y represión de actividades ilícitas y delictivas 
y la información tributaria en poder de la administración de impuestos.

C. Serán gratuitas las consultas presenciales o no documentarias, que sean efectuadas por el sujeto concernido, tanto como el trámite de sus solicitudes de rectificación o actualización que prosperen. La información que se provea por escrito en virtud de las solicitudes de consulta sobre el estado de los registros, o de las peticiones de rectificación o actualización que prosperen, podrán ser cobradas a las mismas tarifas que los operadores tengan establecidas para los usuarios habituales.

ARTÍCULO $5^{\circ}$. CALIDAD DE LA INFORMACIÓN: Las personas responsables de recoger y de actualizar datos para los bancos o archivos, tienen la obligación de efectuar en forma rutinaria o extraordinaria cuando fuere el caso, comprobación sobre la calidad de tales datos y de asegurar que se mantengan tan completos como sea posible para evitar, entre otros, los errores de omisión y para lograr que la recolección, el tratamiento, la utilización y la definición de aquellos se sujeten, además de lo previsto en el artículo anterior, a los siguientes principios:

A. Transparencia, es decir, que la circulación de datos sea libre siempre y cuando se dé cumplimiento a lo dispuesto en la presente ley.

B. Confidencialidad y seguridad, es decir que los bancos y los archivos deben estar protegidos contra los peligros de pérdida, destrucción y uso no autorizado o fraudulento, de la información en ellos contenida.

C. Veracidad y correcta utilización de los datos, para que sean exactos y actualizados, de tal manera que permitan responder sobre la situación real de las personas sobre quien versa.

ARTÍCULO $6^{\circ}$. RESPONSABILIDAD: Las personas naturales o jurídicas que ejerzan la actividad que se regula mediante la presente ley, son responsables por los archivos o bancos de datos de información comercial que posean, así como de su recolección, manejo y divulgación, como son responsables las fuentes por las informaciones que suministren a aquellas.

ARTÍCULO $7^{\circ}$. FUENTES LEGÍTIMAS DE INFORMACIÓN: Los bancos o archivos únicamente podrán recoger y actualizar información proveniente de las siguientes fuentes: 
A. La persona objeto de la información o sus legítimos representantes.

B. Cualquier persona que haya tenido relaciones de índole civil, comercial, administrativa, bancaria o laboral con la persona objeto de la información, siempre y cuando ésta se refiera a los actos, situaciones, hechos, derechos y obligaciones objeto de tales relaciones o derivados de las mismas, sobre las cuales la fuente tenga conocimiento directo.

C. Los registros, documentos o publicaciones a los cuales haya tenido acceso el banco o archivo y de los cuales dará noticias, en los casos previstos en esta ley.

D. Otros bancos o archivos, cuando actúan en calidad de fuentes de información, que serán responsables por la información que suministren, y otras personas naturales o jurídicas que hayan recibido su información de las fuentes mencionadas en éste y en los numerales anteriores y que, por lo tanto, puedan ser fácilmente comprobados.

ARTÍCULO $8^{\circ}$. EXACTITUD DE LA INFORMACIÓN: Los bancos de datos o los archivos estarán obligados a tramitar con sus fuentes de información las solicitudes de actualización y rectificación que presenten las personas por ellos reportadas, en un plazo no mayor de quince (15) días contados desde la fecha de la solicitud. Si vencido el plazo aquí indicado la fuente de datos no se ha manifestado sobre las solicitudes de actualización y/o rectificación, o lo ha hecho en forma negativa, el banco o archivo dispondrá lo necesario para que la difusión de datos controvertidos incluya una constancia sobre el citado trámite.

En todo caso, las solicitudes de actualización y rectificación y la decisión de la fuente de información deberán ser comunicadas por el banco o archivo a los usuarios que hayan recibido esta información sobre el solicitante durante los seis (6) meses anteriores y a quienes habrán de recibirla en el futuro.

ARTÍCULO 90. ELIMINACIÓN DE REGISTROS: Sin perjuicio de lo dispuesto en el artículo anterior, si al efectuar la tramitación de una solicitud de rectificación el banco o archivo encuentra que la que él tiene es inexacta, o no puede ser verificada, deberá rectificarla o eliminarla en su base de datos y tal hecho notificado a las personas que hayan recibido información sobre el solicitante en los últimos seis (6) meses. 
ARTÍCULO $10^{\circ}$ SUMINISTRO DE INFORMACIÓN: Los bancos o archivos pueden suministrar la información por ellos recopilada y actualizada, salvo la que el artículo $15^{\circ}$ de la Constitución considera cubierta por el derecho a la intimidad, a las siguientes personas:

A. A las personas objeto de dicha información a quienes se refiere el artículo $4^{\circ}$ de la presente ley o a sus legítimos representantes o a sus herederos o legatarios si hubieren fallecido, o a cualquier otra persona debidamente autorizada por los anteriores.

B. A los funcionarios de la rama judicial, de la Procuraduría General de la Nación, a la administración de impuestos nacionales, a la Contraloría General de la República, a las Comisiones del Congreso Nacional en los términos del artículo $137^{\circ}$ de la Constitución Nacional y a cualquier otra autoridad que tenga jurisdicción para exigirla.

C. A cualquier persona de quien se sepa con razonable certeza que:

1. La usará para una transacción crediticia que concierne a la persona objeto de la solicitud.

2. La usará para efectos de conferir empleo a la misma persona.

3. La usará para evaluar una solicitud de amparo de seguro.

4. La usará para cualquier otro fin que exija el indagado la asunción de responsabilidades de naturaleza financiera o comercial frente al Estado o a entidades particulares o en relación con una operación legítima de negocios.

PARÁGRAFO: Se exceptúan de lo dispuesto en el numeral 1 del presente artículo los archivos sobre la seguridad nacional y asuntos criminales de que trata el parágrafo 1 del artículo $3^{\circ}$ de la presente ley, los cuales no podrán ser consultados por los interesados.

ARTÍCULO $11^{\circ}$. INFORMACIÓN DE CIRCULACIÓN RESTRINGIDA: Ningún banco o archivo entregará información sobre las condiciones personales, la reputación o forma de vida de persona natural alguna, sin haber informado previamente a tal persona que ha recibido la correspondiente solicitud pero sin que tenga obligación de revelar la identidad del solicitante y sin haber obtenido previamente su autorización escrita. Dicha información se suministrará al interesado dentro de los tres (3) días siguientes a la petición recibida, por cual- 
quier medio que garantice su oportuna recepción, y aquel podrá exigir y obtener el nombre del peticionario, la finalidad de la solicitud de información y su ámbito; tendrá derecho, además, a que en dicha información se incluyan sus aclaraciones y peticiones de rectificación, para conocimiento del peticionario.

La información de que trata el presente artículo, y aquella a la cual se refiere el inciso segundo del artículo tercero de esta ley, podrá ser utilizada en forma anónima, para efectos estadísticos, sondeos de opinión e investigaciones.

PARÁGRAFO: Esta disposición no se aplicará tratándose de la información comercial definida en el artículo $2^{\circ}$.

ARTÍCULO $12^{\circ}$. CADUCIDAD DE LOS REGISTROS: Los bancos de datos o archivos no podrán suministrar información que verse sobre la comisión de delitos contravenciones o faltas disciplinarias luego de que haya transcurrido el plazo de prescripción de la acción penal o disciplinaria o la prescripción o cumplimiento de la pena.

Sin autorización de la persona concernida, tampoco podrán proveer a terceros datos de carácter negativo luego de que hayan transcurrido diez (10) años desde que la correspondiente obligación se extinguió por cualquier medio legal.

\section{ARTÍCULO $13^{\circ}$. RESPONSABILIDAD DE LAS FUENTES DE} INFORMACIÓN: Serán responsables de la exactitud de los datos que revelen, sin perjuicio de la responsabilidad de los bancos o archivos que no verifiquen -pudiendo hacerlo- la información que reciban, o no la rectifiquen cuando fuere el caso, o la usen sobre la base de simples rumores sin fundamento serio o que no sea de conocimiento público.

Antes de suministrar por primera vez informes desfavorables a una base de datos, el proveedor de la misma se cerciorará de notificar personalmente al sujeto concernido. Si tal no fuere el caso, dicha persona será notificada por medio de escrito dirigido a su dirección conocida y, a falta de ésta, por medio de aviso publicado por una vez en diario de circulación nacional, con lo cual se entenderá surtido el trámite legal. Cada vez que se suministre información que pueda ser desfavorable para la persona, ésta deberá ser notificada por escrito de tal hecho, dentro de los siguientes treinta (30) días. 
ARTÍCULO $14^{\circ}$. ACCIONES DE TUTELA: Para instaurar acciones de tutela contra los responsables de bases de datos, con miras a la protección de los derechos fundamentales a la intimidad personal y familiar y al buen nombre, será necesario tramitar previamente una solicitud de actualización o rectificación, según corresponda.

El proceso judicial sólo podrá instaurarse luego de que hayan transcurrido quince (15) días hábiles a partir de la solicitud respectiva.

\section{ARTÍCULO $15^{\circ}$. SUMINISTRO DE INFORMACION FUERA} DEL PAIS: Los bancos de datos o archivos no podrán transmitir datos personales con destino a países cuya legislación no ofrezca garantías análogas a las previstas en la presente ley. Se exceptúan de la aplicación de lo aquí dispuesto las transferencias internacionales de créditos, las transferencias de información para efectos de prestar colaboración con las autoridades judiciales internacionales y cualquiera otra que resulte de la aplicación de tratados o convenios de los que Colombia sea Estado parte.

ARTÍCULO 16. EXCEPCIONES: Sin perjuicio de lo dispuesto en el artículo $2^{\circ}$ de la presente ley, sus disposiciones no se aplicarán a los registros públicos de creación legal, los cuales se seguirán rigiendo por las mismas existentes.

\section{ARTÍCULO 17\%. DETERMINACIÓN DE LA RESPONSABI-}

LIDAD: Las personas y entidades a que se refiere el artículo segundo de la presente ley, serán responsables por los perjuicios ocasionados de conformidad con las normas que regulan la responsabilidad civil, sin perjuicio del ejercicio de la acción de tutela en los casos en que esta proceda. Asimismo, serán responsables penalmente, de acuerdo con las disposiciones sobre la materia, cuando a sabiendas divulguen información falsa, injuriosa o calumniosa.

ARTÍCULO 18. VIGENCIA: Esta ley rige a partir de la fecha de su publicación y las personas y entidades que en ella ejerzan la actividad que se regula, tendrán un plazo de seis meses para adecuarse a su contenido y alcance y deroga las disposiciones que le sean contrarias". 